\title{
1 Regulation of oogenesis in the queen honey bee (Apis mellifera)
}

2 Sarah E Aamidor ${ }^{1}$, Carlos AM Cardoso-Júnior ${ }^{2}$, Januar Harianto ${ }^{3}$, Cameron J Nowell ${ }^{4}$, Louise Cole ${ }^{5}$,

3 Benjamin P Oldroyd ${ }^{1}$, Isobel Ronai ${ }^{1}$

$4 \quad{ }^{1}$ Behaviour and Genetics of Social Insects Laboratory, Ecology and Evolution, School of Life and

5 Environmental Science, Macleay Building A12, University of Sydney, NSW, 2006, Australia;

$6 \quad{ }^{2}$ Departamento de Biologia Celulare Bioagentes Patogênicos, Faculdade de Medicina de Ribeirao

7 Preto,Universidade de Sao Paulo, Ribeirao Preto, Brazil; ${ }^{3}$ School of Life and Environmental Science,

8 Macleay Building A12, University of Sydney, NSW, 2006, Australia; ${ }^{4}$ Drug Discovery Biology, Monash

9 Institute of Pharmaceutical Sciences, Monash University, 381 Royal Parade, Parkville 3052, Victoria,

10 Australia; ${ }^{5}$ Microbial Imaging Facility, 13 Institute, Faculty of Science, The University of Technology

11 Sydney

Correspondance (email: sarah.aamidor@sydney.edu.au)

Key words: ovary activation; ovariole; nurse cell chamber; honeybee; eusociality; phenotypic plasticity.

17

Summary statement: Honey bee queens regulate oogenesis using a different combination of 'checkpoints' to workers, but both castes use the same molecular pathways. 


\section{Abstract}

In the honey bee (Apis mellifera), queen and worker castes originate from identical genetic templates but develop into different phenotypes. Queens lay up to 2,000 eggs daily whereas workers are sterile in the queen's presence. Periodically queens stop laying; during swarming, when resources are scarce in winter and when they are confined to a cage by beekeepers. We used confocal microscopy and gene expression assays to investigate the control of oogenesis in honey bee queen ovaries. We show that queens use different combination of 'checkpoints' to regulate oogenesis compared to honey bee workers and other insect species. However, both queen and worker castes use the same programmed cell death pathways to terminate oocyte development at their caste-specific checkpoints. Our results also suggest that the termination of oogenesis in queens is driven by nutritional stress. Thus, queens may regulate oogenesis via the same regulatory pathways that were utilised by ancestral solitary species but have adjusted physiological checkpoints to suit their highly-derived life history.

\section{Introduction}

In eusocial insects, females develop into either a highly reproductive queen or a nonreproductive worker (Oster and Wilson 1978). In the honey bee, Apis mellifera, queens and workers arise from the same genetic template (genotype), but have radically different morphological and behavioural phenotypes (Snodgrass 1956; Dade 1977; Winston 1987). Queens lack worker-specific characters such as a barbed sting, pollen baskets (corbiculae) and a honey crop, whereas workers generally lack the specialised reproductive organs of the queen such as the sperm-storing spermatheca. Notably, while both queens and workers have ovaries, they differ enormously in the number of ovarioles (the tubes in which oocytes develop). Queens have 150-200 ovarioles per ovary, whereas workers have approximately four (Snodgrass 1956; Rozen 1986; Ronai, Allsopp et al. 2017). The queen's ovaries occupy the majority of her abdominal cavity and can produce up to 2,000 eggs per day (Page and Erickson 1988). Honey bee queens therefore have one of the highest levels of fecundity of any insect (Hodin 2009).

In an activated honey bee ovary, each ovariole contains multiple oocytes (immature eggs) at different stages of development. Oogenesis begins at the tip of the ovariole when a germline cell divides repeatedly to produce what will become an oocyte and a cluster of accompanying nurse cells. The nurse cells provide nutrition and other elements required by the developing oocyte as it travels through the ovariole, in a conveyor-belt fashion, towards the median oviduct (Snodgrass 1956). As the oocyte approaches the oviduct the nurse cells transfer their contents to the oocyte in a process known as nurse cell 'dumping' (Spradling 1993; Cavaliere, Taddei et al. 1998), and die as the oocyte completes its development. Finally, the mature oocyte passes through the median oviduct and is laid.

Worker honey bees, on the other hand, are facultatively sterile (Visscher 1989; Ratnieks 1993). Young workers can switch between 'deactivated' ovaries when the queen is present to 'activated' when the queen is absent (Malka, Shnieor et al. 2007). The mechanisms underlying the reproductive plasticity of workers has been widely investigated (e.g Hoover, 
94 Keeling et al. 2003; Malka, Shnieor et al. 2007; Woyciechowski and Kuszewska 2012;

95 Traynor, Le Conte et al. 2014; Ronai, Oldroyd et al. 2016; Ronai, Oldroyd et al. 2016). Young

96 workers continuously produce new oocytes, but in the presence of a queen, the developing

97 oocytes are aborted during mid-oogenesis via programmed cell death (PCD) (Tanaka and Hartfelder 2004; Tanaka, Schmidt-Capella et al. 2006; Ronai, Barton et al. 2015). The reproductive plasticity of young workers allows them to rapidly activate their ovaries, by switching off the PCD mechanisms, thereby allowing pre-existing immature oocytes to develop. This mechanism likely evolved because there is a fitness premium for the first workers to successfully lay eggs in a queen-less colony (Page and Robinson 1994). A queen signals her presence to the workers via pheromones (Butler 1957; Butler and Fairey 1963; Hoover, Keeling et al. 2003), the most significant of which is queen mandibular pheromone (Butler, Callow et al. 1961). In a colony with a queen, the presence of queen mandibular pheromone and brood pheromones in a worker's environment activates the gene network(s) that initiate PCD in early oocytes of workers (Le Conte, Mohammedi et al. 2001; Ronai, Oldroyd et al. 2016; Hartfelder, Tiberio et al. 2018) .In contrast to workers, the mechanisms underlying the reproductive plasticity of mated queens is unlikely to be regulated by queen mandibular pheromone and brood pheromones, for if they were influenced by these cues, they would be permanently sterile. Nonetheless, queens, like workers, are able to curtail oogenesis in response to environmental cues.

Mated queens exhibit reproductive plasticity under three specific circumstances. First, in temperate zones, queens drastically reduce egg laying in winter (Seeley 1985), becoming reproductively active again in late winter or early spring (Avitabile 1978; Shehata, Townsend et al. 1981). This annual plasticity in oogenesis is likely triggered by decreased availability of fresh pollen combined with declining day length (Mattila and Otis 2007). Second, reproductive swarming; when the queen and approximately half of the colonies workers depart the nest to establish a new colony (Simpson 1959). In preparation for swarming, the workers reduce the frequency at which they feed the queen (Allen 1956; Pierce, Lewis et al. 2007). Probably as a consequence of this reduced feeding, the queen's egg production declines significantly (Allen 1956; Grozinger, Richards et al. 2014). As a result the queen's weight is significantly reduced, which likely allows her to fly more easily when she leaves with the swarm (Seeley and Fell 1981). After the swarm leaves the natal nest, the bees hang in a cluster nearby. While in the cluster the queen's egg production almost ceases (Pierce, Lewis et al. 2007). Only once the swarm moves to its new home and new brood cells are built, does the queen resume egg laying (Ambrose 1976; Winston 1987). Thirdly, commercial queens used in agriculture are often forced to undergo periods when they are prevented from laying due to beekeeping practises (Rhodes, Somerville et al. 2004). Queens produced for sale are sometimes 'banked' within individual cages in a colony for several weeks (Laidlaw and Page 1997). Banked queens are cared for by the colony's workers but lack a comb in which to lay eggs. Queens are often shipped via mail in individual cages with an escort of 5-8 workers that feed and groom the queen, usually for a period of up to 10 days (Laidlaw and Page 1997). Caged queens do not lay eggs, have restricted food, and their abdomens become much reduced in size (Laidlaw and Page 1997). Nonetheless, once the queen is introduced to her new colony she recommences egg laying in a few days (Rhodes, Somerville et al. 2004). 
140 In this study, we investigate the mechanisms that enable honey bee queens to switch

141 between activated and deactivated ovaries. We studied oogenesis in queens by examining

142 the morphological changes in their ovaries when they are prevented from laying in two different social environments; (i) within the colony and (ii) when removed from the colony with a few escorting workers. Since queens and workers originate from the same genetic template, we further investigated whether the reproductive plasticity of queens is regulated by differential expression of the same genes that are associated with the reproductive plasticity of workers, and whether such plasticity is driven by nutritional stress. Specifically, we quantified the expression of genes associated with: PCD (Anarchy, Buffy, Apaf-related killer gene [Ark], long non-coding ovary-1 [Lncov1], Tudor-SN, and Draper); nutrition (target of rapamycin [Tor], Forkhead box O [FoxO], elongation growth factor receptor [Egfr]); Juvenile Hormone production (Krüppel-homolog 1 [Kr-h1]), and vitellogenesis (Vitellogenin $[\mathrm{Vg}]$ and Vitellogenin Receptor $[\mathrm{VgR}]$ ). We hypothesise that the genetic pathways controlling oogenesis in queens would be similar to those seen in workers (i.e. associated with PCD). We further hypothesised that in contrast to workers, where queen mandibular pheromone and brood pheromones are the cue for workers to stop oogenesis, in queens it is nutritional cues that regulate oogenesis. More broadly, we note that in solitary Hymenopterans, nutritional cues are intimately related to oogenesis (Toth, Varala et al. 2007). Thus nutritional cues may also have a role in regulating oogenesis in the queens of advanced eusocial insects (Hunt and Amdam 2005; Dolezal, Flores et al. 2013).

\section{Methods}

\section{Biological material}

Queens $(n=25)$ were removed from their colonies during summer (December 2018). All individuals were mature ( $>6$ weeks old), mated, laying queens of standard Australian commercial stock mostly derived from $A$. m. ligustica.

Queens were randomly assigned to three treatment groups. First, fifteen queens were placed in individual plastic mailing-introduction cages ( $4 \mathrm{~cm} \times 2 \mathrm{~cm}, J Z-B Z$ Queen Cages) used by commercial beekeepers, with five to eight supporting workers and kept in a dark at room temperature. The workers had ad libitum access to water and queen candy (a mixture of caster sugar and honey) to feed the queens. Collectively we refer to these treatments as caged 'ex-colony' (EC). Five queens from this EC group were collected on days 4, 7 and 10 after caging (which is within standard beekeeping practice). Second, five queens with no escorting workers were suspended in their cages between brood frames above a queen excluder in a strong colony. The queen excluder prevented access by the resident queen to the caged queens. Queens were fed by host workers through the mesh of their cages. These queens were collected 10 days after caging. We refer to these queens as caged 'in colony' (IC). Third, the remaining five queens were collected from their colonies at day 0 as the control group. During the course of these experiments two queens died, one in the 10-day $\mathrm{EC}$ group and one in the IC group. Hence there is no data from these two queens.

All collected queens were immediately frozen on dry ice and stored at $-80^{\circ} \mathrm{C}$. Queens were dissected in RNase-free phosphate-buffered saline (PBS) and their paired ovaries were delicately removed. Both ovaries were imaged under a dissecting light microscope (Olympus 
187 SZ40 Stereo Zoom) at 8X magnification in order to measure the ovary 2D area. One of the

188 paired ovaries was randomly chosen and halved. One half was set aside for confocal

189 microscopy and the other for gene expression analysis. The remaining ovary was stored but

190 not used for this study. All dissected ovaries were stored at $-80^{\circ} \mathrm{C}$ until required.

\section{Gene expression in the ovaries}

Total RNA was extracted from each ovary sample $(n=23)$ using TRIzol (Invitrogen). The amount of RNA present per sample was estimated using a Qubit 2.0 Fluorometer (Invitrogen) and samples were diluted to $200 \mathrm{ng} / \mu \mathrm{L}$ with RNase-free water. DNA was removed using a Turbo DNase Kit (Thermo Fisher Scientific). For each sample, cDNA was synthesised from 320 ng of RNA (64 ng/ $\mu \mathrm{L}$ ) using a SuperScript ${ }^{\mathrm{TM}}$ III Reverse Transcriptase Kit (Invitrogen) with Oligo (dT) universal primers with appropriate positive and negative controls. All cDNA samples were diluted to $5 \mathrm{ng} / \mu \mathrm{L}$ with RNase-free water.

We quantified the expression of 11 genes of interest (Anarchy, Buffy, Draper, Egfr, Lncov1, Tudor, Tor, FoxO, Kr-h1, Vg and $V g R$ ) in the queen ovaries using RT-qPCR. Each reaction was run in triplicate with a final volume of $5 \mu \mathrm{L}$ [ $1 \mu \mathrm{L} \mathrm{CDNA}(5 \mathrm{ng} / \mu \mathrm{L}$ ), $2.5 \mu \mathrm{L}$ SYBR Green (Applied Biosystems, Life Technologies) and 1.25 pmol of each primer] using a CFX384 Real-Time System (Bio-Rad). The sequences of the primers and reaction conditions for the 11 genes of interest and four candidate reference genes ( $p R S 5, R P 49$, Ef1a and Actin) are provided in Supplementary Table S1. The reaction efficiency for each primer set was obtained by a standard curve (serial dilution) fitted for each of the genes (Supplementary Table S1). Of the four candidate reference genes, Ef1a and $R f 49$ were found to have the most stable expression using the software BestKeeper (Pfaffl, Tichopad et al. 2004). These two genes have been previously recommended as appropriate reference genes for gene expression studies in honey bees (Lourenço, Mackert et al. 2008; Reim, Thamm et al. 2013). Relative gene expression was calculated according to the efficiency correction formula considering the efficiency of each gene and normalised with the two reference genes (Brito, McHale et al. 2010).

\section{Fixing, staining and confocal imaging of the ovaries}

Ovaries were prepared for staining according to Dallacqua and Bitondi (2014). Briefly, each ovary was fixed and permeabilised in heptane fixative $(0.83 \%$ heptane, $0.067 \% \mathrm{HEM}$ buffer (pH 6.9, 0.1M HEPES, 2mM MgSO4 and $1 \mathrm{mM} \mathrm{EGTA),} \mathrm{0.01 \%} \mathrm{paraformaldehyde} \mathrm{and} 0.0167 \%$ DMSO) for 30 minutes on a shaker, followed by three washes in PBS. The ovaries were then dehydrated with increasing concentrations of ethanol (25\%, 50\%, $75 \%$ and $100 \%)$ and stored over night at $-20^{\circ} \mathrm{C}$. For staining, the ovaries were rehydrated with decreasing concentrations of ethanol in water (75\%,50\% and $25 \%)$ and then washed three times in PTw (PBS and 0.1\% Tween20). Ovaries were refixed in Triton fixative (PBS, $0.1 \%$ Triton X-100, $4 \%$ paraformaldehyde and 10\% DMSO) for 20 min and washed three times in PTw. In order to further permeabilise the tissue, samples were incubated for 10 minutes in $20 \mu \mathrm{g} / \mathrm{mL}$ proteinase $\mathrm{K}$ followed by two washes in $1 \%$ glycine and three washes with PTw. The ovaries were refixed in Triton fixative for 20 minutes and washed six times in PTw to remove all traces of fixative. Ovaries were then stained for actin with ActinGreen 488 (Invitrogen) for 30 minutes, washed three times with PTw and counterstained for nucleic acid with DAPI 
$234(0.004 \% \mathrm{v} / \mathrm{v})$ (Sigma) for five minutes followed by three washes in PTw. The ovaries were

235 then split into clusters of one to four ovarioles and mounted on slides in Fluoroshield (Sigma)

236 with glass cover slips. (During fixation one ovary from the control group was lost and therefore not imaged). Slides were imaged using a ZEISS LSM 800 confocal microscope using 450 and $488 \mathrm{~nm}$ excitation wavelengths to image the nucleic acid and actin respectively. Single focal plane and z-stacks were taken using either a 10x or 20x objective. Z-stack images were processed to create a two-dimensional maximum intensity projection (MIP). All images were acquired, stitched and processed using ZEN blue software.

\section{Image analysis}

Images were analysed using a custom macro in the Fiji distribution of ImageJ (Schindelin et. al., 2012). Stereo images were used to calculate total area of both ovaries (one image for each individual ovary). Confocal images were enhanced using the ImageJ gamma function at 0.6 to increase contrast. For each stitched image, the oocytes and Nurse Cell Chambers (NCC) in each ovariole were traced by hand and the resulting ROls saved for future validation if required.

Confocal image analysis is described in detail in Supplementary Materials and Methods S1 and available for download from https://doi.org/10.26180/13557764. Briefly, oocytes and $\mathrm{NCC}$ in each string were outlined using the freehand region of interest (ROI) tool on maximum $Z$ projections of each image set from the most developed intact oocyte (oviduct end) until the oocytes and NCC could no longer be distinguished in the late germarium (Büning 1994). Each ROI was then used to calculate the equivalent spherical radius by using the maximum and minimum Feret's diameter to first calculate the oblate volume (due to the 'objects' - oocyte or NCC - being non-spherical) of the object and then to calculate the equivalent spherical radius. The data was logged and then further analysed using Excel and GraphPad Prism. In order to visualise the changes along the entire ovariole a locally weighted smoothing (LOESS) function was added on the scatterplot output using the 'loess() ' function from the base `stats' package in $\mathrm{R}$ (version 4.0.3).

\section{Statistical analysis}

267 To determine the effects of treatment group on the morphological features and gene 268 expression of the ovariole, we modelled the data using generalised linear models (GLM) 269 with a normal link function. The dependent variable was unit size or position in the ovariole, or the fold change in gene expression. The independent (fixed) factor was the treatment group (control (Day 0), EC day 4, EC day 7, EC day 10 and IC day 10).

272 All covariates were ordinal, thus model significance was tested with an analysis of variance

273 (ANOVA) using the Wald Chi-square test statistic and Type 3 error. Where statistical results 274 indicated significant differences at $p<0.05$, estimated marginal means (EMM) we used to 275 develop linear estimates of pairwise comparisons and then tested using Tukey's honestly 276 significantly different (HSD) test to identify significant differences at $p<0.05$. 
277 Analyses were performed in R (version 4.0.3). GLMs were performed using the 'Anova()`

278 function from the 'cars' package (version 3.0-10) while post-hoc analyses were performed

279 using the `emmeans()` function from the `emmeans` package (version 1.5.3).

\section{Results}

282

283

\section{Oogenesis in a laying queen}

Below we provide a description of normal oogenesis, obtained from our high-resolution confocal images of the ovaries of queens freshly taken from their colonies (controls; Day 0). Descriptions are also based on the existing honey bee ovary morphology literature (Snodgrass 1956; Gutzeit, Zissler et al. 1993; Büning 1994).

At the apical tip of each ovariole is the terminal filament (Figure $1 \mathrm{Bi}$ ) and germline stem cells (Figure $1 \mathrm{~B}$ ). The early germarium stage is characterised by a single germ cell dividing repeatedly to produce a cluster of cells (also known as cystocyte rosettes) around actin polyfusomes (Figure $1 \mathrm{Bi}$ ). Subsequently, one of the cells differentiates into the oocyte, while the remaining cells of the cluster become the nurse cells that will nourish the developing oocyte. Actin fusomes also rearrange into ring canals (Figure $1 \mathrm{Bii}$ ), connecting the oocyte to its accompanying nurse cells.

During the mid-germarium stage, oocytes slowly increase in size and are distinguishable from their accompanying nurse cells (Figure $1 \mathrm{~A}$ ). By the late germarium stage, the oocyte is located towards the oviduct end relative to its accompanying nurse cells (Figure $1 \mathrm{~A}$ ).

The vitellarium stage is defined by the oocyte becoming encased in a layer of somatic follicle cells (Figure $1 \mathrm{Ci}$ ) and the accompanying nurse cells forming a Nurse Cell Chamber (NCC)

304 (Figure $1 \mathrm{~A}$ and $\mathrm{C}$ ). By both qualitative and quantitative analysis of the confocal images, we observed the oocyte and the NCC growing at different rates during the vitellarium stage (Figure 2). Initially the NCC is larger than the oocyte (Fig. 1C) until a point that we define as the 'tipping point' when the developing oocyte first exceeds the size of its accompanying NCC (Figure $1 \mathrm{~A}$ and 2). After the tipping point the late vitellarium stage begins and the oocyte grows rapidly (Figure $1 \mathrm{~A}$ and 2 ). And the nurse cells undergo developmental programmed cell death (King 1970), ultimately transferring their remaining cytoplasm into the oocyte in a process termed nurse cell dumping (Figure $1 \mathrm{~A}$ and $\mathrm{D}$, Figure 2 ). This nurse cell dumping results in the complete collapse of the NCC ('dnc' in Figure 1A; see also Figure 1D). At the final stage of oogenesis, the oocyte is fully formed and situated the oviduct end of the ovariole (Figure 1A and 1D). The pedicel (also known as the basal stalk), a constriction at the entry to the oviduct which prevents the oocyte from moving into the oviduct until it is ready to be laid can also be seen clearly by confocal microscopy (Figure $1 \mathrm{~A}$ and 1D).

\section{Oogenesis in queens prevented from oviposition}

Stereomicroscopy showed that caging, both ex-colony (EC) and in-colony (IC), resulted in 
323 (Figure $3 \mathrm{~A}$ ). We found that mean ovary area differed significantly among treatments (Wald $\chi^{2}=96.25$, d.f. $=4, P<0.0001$; Figure 3 B). Queens caged EC had significantly smaller ovary area compared to the controls. Although queens caged IC for 10 days did not show such an extreme reduction in ovary area, they too were smaller than the controls (Figure $3 \mathrm{~B}$ ).

Overall, confocal microscopy showed that there was no significant effect of caging treatments on the total number of oocytes (Wald $\chi^{2}=6.04$, d.f. $=4, P=0.196$; Figure S1). However, the size of the most mature (i.e. maximum-sized) oocyte was significantly reduced by the caging treatments (Wald $\chi^{2}=18.79$, d.f. $=4, P<0.001$; Figure 2 and S2 A). The size of the most mature oocyte was similar in queens that were caged EC for 10 days and the control queens (Figure S2 A). In contrast, the maximum size of the NCC was not significantly affected by the caging treatments (Wald $\chi^{2}=8.97$, d.f. $=4, P=0.062$; Figure 2 and S2 B). In addition, the minimum size of oocytes and NCC did not significantly change as a result of caging treatments (Wald $\chi^{2}=5.43$, d.f. $=4, \mathrm{p}=0.246$; Wald $\chi^{2}=1.48$, d.f. $=4, \mathrm{p}=0.830$; Figures $S 2 \mathrm{C}$ and $\mathrm{D}$ respectively).

Although the number of identifiable oocytes per ovariole was unaffected by treatment (Figure S1), we nonetheless observed changes in the developmental gradient of oocytes along the ovarioles between treatments. The cells of the early germarium did not extend to the apical end of the ovariole in the caged queens (Figure $1 \mathrm{E}, \mathrm{H}, \mathrm{K}$ and $\mathrm{N}$ ). The early vitellarium stage in the EC caged queens had seemingly healthy NCCs, but the oocytes were misshapen and starting to deteriorate (Figure $4 \mathrm{~A}$, arrows). This deterioration of the oocyte progressively intensified as the days of EC caging increased (Figure $1 \mathrm{I}, \mathrm{L}$ and $4 \mathrm{~B}$, arrow). In contrast, the oocytes in the early vitellarium stage in IC caged queens (Figure 10 ) seemed similar to the control queens. The difference between the volume of the oocyte and its accompanying NCC provides a measure of the combined changes in the units (oocytes and $\mathrm{NCC}$ ) along the ovariole (Figure 2, green line). In all the caged treatments the tipping point, marking the start of the late vitellarium stage, significantly shifted towards the oviduct end of the ovariole relative to control queens (Wald $\chi^{2}=119.43$, d.f. $=4, p=0.0001$; Figure 2 and S3). This shift suggests that there was a delay in the maturation of the oocytes in the caged queens, which in turn reduced the number of mature oocytes present in the ovariole. The tipping point for the IC caged queens was at a similar position in the ovariole to those seen in queens that had been caged EC for four days (Figure 2 and Figure S3).

By the late vitellarium stage several structural abnormalities could be identified as a result of caging. In both EC and IC the cytoplasm bridges (ring canals) that normally connect the oocyte to its accompanying NCC were sometimes lost, resulting in an empty and elongated sheath between them (Figure $4 \mathrm{C}$ arrows). In addition, the link between the oocyte and NCC units appeared to be elongated (Figure $4 \mathrm{C}$ and $\mathrm{K}$, arrows compared to $\mathrm{F}$, arrow). As a proxy for successful maturation of a mature oocyte, we measured the proportion of NCCS dumping by measuring the volume difference between of the maximum and the last NCC. Overall, we found that the proportion of dumping was significantly decreased by caging (Wald $\chi^{2}=18.86$, d.f. $=4, \mathrm{p}=0.001$; Figure 2 and S4). Interestingly, in EC caged queens, some nurse cell dumping occurred prematurely, just after the tipping point, when the oocyte was still underdeveloped (Figure $4 \mathrm{D}$ arrowhead). As the days of EC caging progressed, the oocyte also appeared increasingly underdeveloped when nurse cell dumping occurred (Figure $4 \mathrm{E}$ and F). By day seven of EC caging, some NCCs were at the 
oviduct end of the ovariole, but had not yet undergone PCD (Figure $1 \mathrm{~J}$ ). In addition, there were some NCCS that had not collapsed even though the nurse cells had undergone PCD (Figure 4 B, F and G).

The oocytes closest to the oviduct undergo degeneration during the late vitellarium stage in EC caged queens. Initially, these degrading oocytes disconnect from their accompanying follicle cells (Figure $4 \mathrm{H}$ arrow). As degradation progresses, the oocyte begins to collapse (Figure $4 \mathrm{I}$, white arrow) and undergo PCD (Figure $4 \mathrm{~J}$ arrow), until it degrades completely (see Figure $1 \mathrm{~J}$ ). At the oviduct end of the ovariole, an actin aggregation accumulates as the days of EC caging increase (Figure $1 \mathrm{G}, \mathrm{J}$ and $\mathrm{M}$, arrow). In contrast, in the queens caged IC, the late vitellarium stage oocytes looked similar to those of the control and there appeared to be no actin aggregation (Figure $1 \mathrm{P}$ ).

In summary, confocal microscopy demonstrated that queens caged outside the colony (EC), had abnormal oogenesis as early as the fourth day post caging (Figure 1E, F, G). Throughout the days of EC caging the ovary area decreased, and the length of the germarium increased. This lengthening was a consequence of delayed growth of both the oocytes and NCC, as evidenced by the tipping point shifting towards the oviduct end. This latter shift resulted in underdeveloped, small, oocytes in the late vitellarium stage. By day seven post EC caging, only half of the NCCs completed 'dumping'. In contrast, caging in the colony (IC) did not have such an extreme effect on queen ovaries. Although the size of the ovary slightly decreased as a result of caging IC, it is possible that this decrease was a result of the increase in the length of the germarium. However overall, queens caged IC retained healthy oocytes and may have continued some egg laying.

\section{Gene expression}

The expression level of five (Anarchy, Buffy, Tudor, Lncov1 and Draper) of the six PCDassociated genes investigated increased with the duration of caging EC and IC (Wald $\chi^{2}$, $\mathrm{p}<0.05$, table S2; Figure S5 A-E). The only exception to this pattern was Ark, where we found no effect of treatment on its expression levels (Wald $\chi^{2}=5.43$, d. $f=4, p=0.246$, table S2, Figure S5 F).

The expression of the four genes associated with nutrition sensitivity pathways and $\mathrm{JH}$ ( $\mathrm{Kr}$ h1, Egfr, Tor and Foxo) were significantly affected by the caging treatments (EC and IC) (Wald $\chi^{2}, p<0.05$, Figure S5 G-J, Table S2). These genes significantly increased in expression by day 10 of caging EC. The only gene that differed from this pattern was Foxo, which initially increased in expression before returning to levels similar to those seen in the control by day 10 of both EC and IC caging (Figure S5 J).

Gene expression of $\mathrm{Vg}$, one of the two genes associated with vitellogenesis, was not affected by EC or IC caging (Wald $\chi^{2}=4.44, d . f=4, \mathrm{p}=0.35$, Figure S5 K), and was extremely low. The expression of its receptor, $V g R$, was also not affected by caging treatments (Wald $\chi^{2}=8.4$, d.f $=4, \mathrm{p}=0.077$, Figure S5 L).

\section{Discussion}


418 Our study reveals that the control of oogenesis in honey bee queens uses different checkpoints to workers but similar genetic pathways. We identified three putative reproductive 'checkpoints' (also known as 'control points' in Ronai, Vergoz et al. 2016) that regulate oogenesis in honey bee queens. First, there is an absence of visible germline cells. This reduction in germline cells could either be due to suppression of stem cell differentiation (Figure 5 Checkpoint 1 ) or the early germline cell clusters are undergoing PCD (Figure 5 checkpoint 2).

$P C D$ in the early germarium has previously been identified in virgin honey bee queens prevented from mating (Berger and Abdalla 2005; Cruz-Landim, Patrício et al. 2006) and in sterile honey bee workers (Tanaka, Schmidt-Capella et al. 2006; Ronai, Barton et al. 2015; Duncan, Hyink et al. 2016). These early checkpoints are also found in Drosophila melanogaster females that are under nutritional stress (Drummond-Barbosa and Spradling 2001; Jenkins, Timmons et al. 2013). Secondly, we found degradation of the oocytes in caged queens at the early vitellarium stage (Figure $1 \mathrm{I}, \mathrm{L}$ and $4 \mathrm{~A}, \mathrm{~B}$ ). This checkpoint is not known to occur in any other hymenopteran species, or in insects in general, and is potentially unique to honey bee queens (Figure 5 checkpoint 4). Thirdly, mature oocytes degenerate in the late-vitellarium stage in honey bee queens prevented from laying (see also Cruz-Landim, Patrício et al. 2006) (Figure $1 \mathrm{G}, \mathrm{J}, \mathrm{M}$ and $4 \mathrm{I}, \mathrm{J}$ ). This checkpoint is also known to occur in another hymenopteran the parasitoid wasp (Nasonia vitripennis) (Hopkins and King 1964) but has not been shown in honey bee workers or other insects (Figure 5 checkpoint 5). Thus, it appears that honey bee queens have two additional checkpoints when compared to workers.

Our results indicate that honey bee queens and workers modulate oogenesis using a different combination of checkpoints to meet their different life history needs. In sterile workers the last checkpoint is at the late germarium stage (Tanaka and Hartfelder 2004; Ronai, Barton et al. 2015). This late germarium checkpoint is also found in nutritionally stressed Drosophila females (Drummond-Barbosa and Spradling 2001; Jenkins, Timmons et al. 2013) and other insects (Velentzas, Nezis et al. 2003; Uchida, Nishizuka et al. 2004; Mpakou, Velentzas et al. 2011). For honey bee workers, investing in oogenesis when there is no prospect of producing offspring is wasteful (Berger and da Cruz-Landim 2009). Therefore, it is advantageous for them to abort oocyte production before vitellogenesis, which is the most costly stage of oogenesis (Giorgi and Deri 1976; Drummond-Barbosa and Spradling 2001; Ronai, Vergoz et al. 2016). However, when the queen is absent or lost, there is clearly a fitness advantage for workers that are able to quickly switch on oogenesis (Page and Robinson 1994). In contrast to workers, as shown in our study, queens use a combination of checkpoints that act at later stages of oocyte development. These later checkpoints allow the queen to reabsorb the oocytes and therefore preserve invaluable resources if the egg cannot be laid. Therefore, queens slow down the rate of oocyte production while continuing to produce oocytes.

PCD is an important mechanism for modulating oogenesis in insects and our morphological results support this idea by showing clear evidence of PCD in the ovarioles of caged honey bee queens. Therefore, it was unsurprising to find direct evidence of cell death indicated by the higher expression levels of the phagocytosis engulfment receptor gene Draper 
464 (Etchegaray, Timmons et al. 2012) in caged queens. Furthermore, we have shown an 465 upregulation of genes from two independent PCD pathways in honey bee queens: one that 466 involves Anarchy and Buffy, a mitochondrial regulatory gene network associated with PCD 467 (Tanner, Blute et al. 2011) and another, the Lncov1/Tudor-SN complex, which interferes 468 with effector caspase activity (Hartfelder, Tiberio et al. 2018). Interestingly, the expression pattern of Anarchy and Buffy in caged queens is not the same as in virgin queens with nonactivated ovaries (Ronai, Oldroyd et al. 2016). Rather, their expression patterns are correlated with the suppression of oogenesis in workers exposed to the queen (Ronai, Oldroyd et al. 2016). Interestingly, expression of Ark, a pro-apoptotic gene that initiates the caspase cascade resulting in PCD (Cain, Bratton et al. 2002; Dallacqua and Bitondi 2014), remained constant across our treatments. In virgin queens with non-activated ovaries, Ark is downregulated but is not differentially expressed between sterile and laying workers (Rodriguez, Oliver et al. 1999; Dallacqua and Bitondi 2014; Ronai, Oldroyd et al. 2016). Thus, our results suggest that under stressful environmental conditions queens modulate their oogenesis using the same mechanism (PCD) as workers and do not revert to a virgin-like status.

A critical process for the maturation of an oocyte in insects is the accumulation of vitellogenin, the main egg yolk protein (Raikhel and Dhadialla 1992; Tufail and Takeda 2008). Vitellogenin is mostly synthesised in the fat body and then transferred to the oocyte via the vitellogenin receptor $(\mathrm{VgR})$ (Engels 1974). Therefore, it was not surprising that $\mathrm{Vg}$ expression in the ovary was extremely low (Guidugli, Nascimento et al. 2005; Cardoso - Jú nior, Oldroyd et al. 2021) and did not change as a result of the treatments. However, previous studies have used $V g R$ expression levels as a proxy for the reproductive state of honey bee workers (Guidugli-Lazzarini, do Nascimento et al. 2008; Cardoso - Júnior, Oldroyd et al. 2021), therefore one may expect $V g R$ expression levels to decrease as a result of the reduced oogenesis in caged queens. Our results suggest that under stressful conditions queens potentially keep $V g R$ levels constant in the ovaries in order to be able to swiftly provide vitellogenin and restore oogenesis when the environmental conditions improve.

494

Our results emphasise the significance of the queens' environment on her reproductive capacity and suggest that nutrition and a normal social environment are necessary for regular oogenesis. We observed a distinct difference in the effects of caging, between EC and IC on oogenesis. Queens caged within the colony had healthier ovaries and oocytes than externally caged queens, in which oogenesis was more severely disrupted. This difference may be linked to the amount of care provided by the workers, particularly the quantity and quality of food fed by the escort workers to the queens EC relative to that which could be provided IC (Szabo 1974). As is standard beekeeping practise, the only source of nutrition available to the escort workers in our external cages was 'queen candy' (Laidlaw and Page 1997). While candy is rich in carbohydrates, it lacks fat and protein, the latter being essential for oogenesis (Fine, Shpigler et al. 2018). Thus, one would expect the ability of escort workers to feed the queen in their care with glandular secretions is severely curtailed because the workers themselves are nutritionally stressed.

Caging queens both EC and IC influenced the expression of genes associated with the 510 nutrient sensitive pathways Tor and EGFR in our study. We suggest that the upregulation of 
511 the nutrition-sensitive genes in the caged and banked queens was due to nutritional stress.

512 FoxO, a downstream target gene of Tor and Egfr, is also upregulated in nutritionally-stressed

513 honey bee workers (Wheeler, Buck et al. 2014; Cardoso - Júnior, Oldroyd et al. 2021) and in

514 nutritionally-stressed solitary insects such as Drosophila (Jouandin, Ghiglione et al. 2014).

515 However, Tor has been shown to be downregulated in ovaries of nutritionally-stressed

516 Drosophila (Pritchett and McCall 2012; Smykal and Raikhel 2015) and mosquitoes (Hansen,

517 Attardo et al. 2005; Perez-Hedo, Rivera-Perez et al. 2014). The up-regulation of $k r$ - $h 1$, a

518 proxy for juvenile hormone (JH) titres (Minakuchi, Namiki et al. 2009; Belles and Santos

519 2014; Lago, Humann et al. 2016) observed in the queens caged both EC and IC is consistent

520 with higher levels of JH seen in non-reproductive honey bee workers (Robinson, Strambi et

521 al. 1992) and in nutritionally stressed Drosophila (Terashima and Bownes 2004) Therefore,

$522 \mathrm{JH}$ possibly works as an intermediate regulator of adult ovary activation in both honey bee

523 castes.

524

525

526

527

Although more studies need to be conducted to assess the effect of nutrition quantity and quality on honey bee queen oogenesis, our study suggests that nutrition could serve as a cue for the suppression of oogenesis in queens. Our findings accord with behavioural observations (Allen 1956; Pierce, Lewis et al. 2007) in which queens are fed less during swarming. In our particular study, IC queens acquired their nutrition via trophalaxis from colony workers through their cage. Food obtained from free-running nurse bees would be almost certainly of higher quality to that available to the EC queens. Whilst nutrition is not the only environmental difference between queens cages EC and IC, we suggest that food is a major factor that contributed to the nearly-normal ovary morphology of the IC queens, and the loss of oocytes in the EC queens. Nutrition also regulates oogenesis in solitary insects such as Drosophila (Drummond-Barbosa and Spradling 2001; Gruntenko, Bownes et al. 2003; Barth, Szabad et al. 2011).

Our study has practical ramifications for beekeepers. It is clear that queens caged in the colony fare better than queens caged externally to the colony, and that keeping queens within the colony environment should be the preferred method for queen storage. It is suggested that the period of caging should be minimised. Likely, reformulating the candy diet for caged queens and their escorts to include pollen as a source of protein and fat would enhance queen welfare in the mail, and we recommend that this be investigated in a future study.

In conclusion, although queens and worker honey bees share the same regulatory template, they have diverged in how they regulate oogenesis. Reproductive division of labour between castes is fundamental for the evolution of eusociality in the social insects. One explanation of the creation of castes is the "reproductive ground plan hypothesis" (WestEberhard 1987) which suggests that the queen and worker castes evolved from a decoupling of the reproductive and foraging stages of a solitary ancestral insect from which contemporary eusocial bees are derived (Amdam, Norberg et al. 2004). This decoupling resulted in the molecular, morphological and behavioural differences between the queen and worker castes but preserved the underling pathways that regulate nutrition and

555 reproduction. It is proposed here that the reproductive divergence of queen and worker 556 honey bees is achieved through different oogenesis checkpoints but the same PCD 
557 pathways in order to modulate oogenesis and to meet the reproductive divergence of the 558 two castes.

559

560

561 Acknowledgements. To Rhiarn Hoban for drawing the detailed ovariole structure; to

562 Mackenzie R. Lovegrove for her assistance in trouble shooting the fixation stages of the

563 ovarioles and to the members the Behaviour and Genetics of Social Insects Lab for their

564 assistance and advice.

565 Conflict of interests. We have no conflict of interests.

566 Data archiving. All supporting datasets for this paper are available as part of the electronic

567 supplementary material.

568 Funding. This work was funded by the Australian Research Council project DP180101696.

569

570 


\section{$571 \quad$ Figure 1}

572 Oogenesis in honey bee queens. (A) A schematic representation of oogenesis in a mated

573 laying queen with the four regions: terminal filament; germarium; vitellarium; and pedicel

574 ( $\mathrm{nc}=$ nurse cell, oo= oocyte, $\mathrm{ncc}=$ nurse cell chamber, $\mathrm{s}=$ sheath, $\mathrm{dnc}=$ dumped nurse cell,

575 and $\mathrm{fc}=$ follicle cell); $\mathrm{B}-\mathrm{D}$. Ovaries of a control queen: (B) terminal filament and early

576 germarium; (Bi) magnification of terminal filament and actin polyfusomes; (Bii)

577 magnification of ring canals; (C) early vitellarium; (Ci) magnification of follicle cells; and (D)

578 late vitellarium.

579 E-G. Ovaries of a queen that had been caged EC for four days: (E) terminal filament and

580 early germarium; (F) early vitellarium; and (G) late vitellarium showing actin aggregation

581 (arrow).

582 H-J. Ovaries of a queen that had been caged EC for seven days: $(H)$ terminal filament and

583 early germarium; (I) early vitellarium; and (J) late vitellarium showing actin aggregation

584 (arrow).

585 K-M. Ovaries of a queen that had been caged EC for ten days: (K) terminal filament and early

586 germarium; (L) early vitellarium; and (M) late vitellarium showing actin aggregation (arrow).

587 N-P. Ovaries of a queen that had been caged IC for ten days; (N) terminal filament and early

588 germarium; $(O)$ early vitellarium; and $(P)$ late vitellarium. Ovaries were stained for nuclei

589 (magenta) and actin (green). Scale bars $100 \mu \mathrm{m}$ and magnified insets $10 \mu \mathrm{m}$.

590

591

592

Figure 2

593

Dynamics of oogenesis in honey bee queens. The mean radius size $(\mu \mathrm{m})$ of the oocytes (red line) and nurse cell chambers (NCC) (blue line) derived from averaged data for the control, caged EC days 4, 7 and 10 and caged IC for day 10 IC treatment groups. The difference

595 between the size of the paired NCC and oocyte is indicated (green line). The cell position

596 represents the unit number along the chain in the ovariole with the proximal oocyte at the

597 oviduct end designated as position 0 (see Materials and Methods S1). The amount of NCC

598 dumping (purple line) and tipping point (orange circle) are indicated for each group.

599

600

Figure 3

601 Change in ovary area of honey bee queens from the control, caged in-colony (IC) $(4,7$ or 10

602 days) or caged Ex-colony (EC) (10 days) treatment groups. (A) Light microscopy image of a

603 representative queen ovary from each treatment group (scale bar $2 \mathrm{~mm}$ ). (B) Mean area

$604\left(\mathrm{~mm}^{2}\right)$ of queen ovaries across treatment groups ( $\mathrm{n}=4$ control, caged IC 10 days and caged

605 EC 10 days; $n=5$ caged EC 4 and 7 days). Error bars are SE of the means. Different letters (a-

606 c) represent statistical significance $(p<0.05)$.

607

608 Figure 4

609 Oogenesis abnormalities in honey bee queen ovarioles after caging for 4, 7 and 10 days ex-

610 colony (EC) and 10 days in-colony (IC). (A) EC four days early vitellarium. Misshapen oocytes

611 (arrows) among healthy-looking nurse cell chambers; (B) EC 10 days late vitellarium. Some

612 oocytes are underdeveloped and misshapen (arrow). There is also brightly-stained

613 fragmented nucleic acid, suggesting premature programmed cell death of nurse cells but

614 with no chamber collapse (arrow heads). Mature oocytes undergoing degradation (asterisk);

615 (C) EC 7 days late vitellarium. The cytoplasm bridge is lost, disconnecting the oocyte from its

616 nurse chamber and the connection between the oocyte and the next NCC is deteriorated

617 (arrows); (D) EC 4 days late vitellarium. The nurse cell dumping (arrow head) is premature, 
618 occurring for an insufficiently-developed oocyte immediately after the 'tipping point'

619 (yellow arrow). A mature oocyte is collapsing (asterisk); (E) EC 7 days early and late

620 vitellarium. The nurse cell dumping (arrow heads) is premature, occurring immediately after

621 the tipping point (yellow arrow). Mature oocytes are undergoing degradation (asterisk); (F)

622 EC 10 days vitellarium. Premature nurse cell dumping (arrow head) is occurring immediately

623 after the tipping point (yellow arrow) or no nurse cell dumping at all (arrows). The most

624 developed oocytes are degrading (asterisk); (G) EC 4 days late vitellarium. Programmed cell

625 death of the nurse cells has occurred, but the nurse cell chamber has not collapsed (arrow).

626 A mature oocyte is collapsing (asterisk); (H) EC 7 days late vitellarium. The oocyte has

627 disconnected from its surrounding follicle cells (arrow) indicating the beginning of its

628 degradation. Brightly-stained fragmented nucleic acid are being transferred to the oocyte

629 following NCC dumping (arrow head); (I) EC 10 days late vitellarium. Structural collapse of

630 an oocyte (arrow) with premature NCC dumping occurring (arrow head) immediately after

631 the tipping point (yellow arrow). The most mature oocyte is completely degraded (asterisk);

632 (J) EC 10 days late vitellarium. The bright white dots in the mature oocyte are a sign of

633 programmed cell death (arrow) and the most mature oocyte has completely collapsed

634 (asterisk); (K) IC 10 days early vitellarium. The connection between the oocyte and its

635 preceding NCC is deteriorating (arrows). $00=$ oocyte; $\mathrm{NCC}=$ nurse cell chamber. Ovarioles

636 have been stained for nucleic acid (DAPI). Scale bars $100 \mu \mathrm{m}$.

637

638

639

Figure 5

640

The oogenesis checkpoints in insects. (A) position of each checkpoint along an ovariole; (B)

641

checkpoints used by the honey bee (Apis mellifera) mated queen, virgin queen, worker;

642

solitary insect the fruit fly (Drosophila melanogaster); and another social insect the

643

644

parasitoid wasp (Nasonia vitripennis).

645 Number of visible oocytes along an ovariole of honey gee queens from the control, caged in-

646 colony (IC) (4, 7 or 10 days) or caged Ex-colony (EC) (10 days) treatment groups. $n=4$

647 control, caged IC 10 days and caged EC 10 days; $n=5$ caged EC 4 and 7 days. Error bars are

648 SE of the means.

649

650

Figure S2

651 Spherical radius $\left(R_{\text {eq }}\right)(\mu \mathrm{m})$ of oocytes and NCC of honey bee queens from the control, caged

652 in-colony (IC) (4, 7 or 10 days) or caged Ex-colony (EC) (10 days) treatment groups. (A)

653 maximum oocyte radius; (B) maximum nurse cell chamber radius; (C) minimum oocyte

654 radius; (D) minimum nurse chamber radius. Sample size see Figure S1. Error bars are SE of

655 the means. Bars with a different letter are significantly different $(p<0.05)$.

656

657

Figure S3

658 Position of the oocyte in the ovariole when the tipping point occurs. Honey bee queens

659 from the control, caged in-colony (IC) (4, 7 or 10 days) or caged Ex-colony (EC) (10 days)

660 treatment groups. Sample size see Figure S1. Error bars are SE of the means. Bars with a

661 different letter are significantly different $(p<0.05)$.

662

663 Figure S4 
664 Extent of nurse cell dumping in honey bee queens from the control, caged in-colony (IC) (4,

6657 or 10 days) or caged Ex-colony (EC) (10 days) treatment groups. Sample size see Figure S1.

666 Error bars are SE of the means. Bars with a different letter are significantly different $(p<$

667 0.05).

668

669 Figure S5

670 Gene expression in the ovaries of honey bee queens from the control, caged in-colony (IC)

671 (4, 7 or 10 days) or caged Ex-colony (EC) (10 days) treatment groups. Genes related to

672 program cell death (A) Anarchy (B) Lncov-1 (C) Tudor (D) Buffy (E) Draper and (F) Ark. Genes

673 related to nutrition (G) Kr-h1; (H) Egfr; (I) Tor and (J) FoxO. Genes related to vitellogenesis (K)

$674 V g$ and (L) VgR. Sample size see Figure S1. Boxplot whiskers represent minimum and

675 maximum values, the box is defined by 25 th percentile, median and 75 th percentile. Bars

676 with a different letter are significantly different $(p<0.05)$.

677

678 
679

680

681

682

683

684

685

686

687

688

689

690

691

692

693

694

695

696

697

698

699

700

701

702

703

704

705

706

707

708

709

710

711

712

713

714

715

716

717

718

719

720

721

722

723

\section{References}

Allen M.D. (1956) The behaviour of honeybees preparing to swarm. The British Journal of Animal Behaviour 4(1): 14-22.

Ambrose J.T. (1976) Swarms in transit. Bee World 57(3): 101-109.

Amdam G.V., K. Norberg, M.K. Fondrk, R.E. Page. (2004) Reproductive ground plan may mediate colony-level selection effects on individual foraging behavior in honey bees. Proc. Natl. Acad. Sci. 101(31): 11350-11355.

Avitabile A. (1978) Brood rearing in honeybee colonies from late autumn to early spring. J Apic Res 17(2): 69-73.

Barth J., J. Szabad, E. Hafen, K. Köhler. (2011) Autophagy in Drosophila ovaries is induced by starvation and is required for oogenesis. Cell Death Differ. 18(6): 915-924.

Belles X., C.G. Santos. (2014) The MEKRE93 (Methoprene tolerant-Krüppel homolog 1-E93) pathway in the regulation of insect metamorphosis, and the homology of the pupal stage. Insect Biochem. Mol. Biol. 52: 60-68.

Berger B., F.C. Abdalla. (2005) Programmed cell death during ovarian differentiation in queens of Apis mellifera linne, 1758 (Hymenoptera, Apini). Braz. J. morphol. Sci 22(1): 1-4.

Berger B., C. da Cruz-Landim. (2009) Ultrastructural analysis of the effect of mating delay on cell death in the ovaries of virgin honey bee (Apis mellifera L.) queens. J Apic Res 48(1): 60-66.

Brito R., M. McHale, B. Oldroyd. (2010) Expression of genes related to reproduction and pollen foraging in honey bees (Apis mellifera) narcotized with carbon dioxide. Insect Mol. Biol. 19(4): 451-461.

Büning J. (1994) The insect ovary: ultrastructure, previtellogenic growth and evolution, in: Chapman and Hall (Eds.), Tissue and Cell, Elsevier Ltd, New York.

Butler C. (1957) The control of ovary development in worker honeybees (Apis mellifera). Experientia 13(6): 256-257.

Butler C., E.M. Fairey. (1963) The role of the queen in preventing oogenesis in worker honeybees. J Apic Res 2(1): 14-18.

Butler C.G., R.K. Callow, N.C. Johnston. (1961) The isolation and synthesis of queen substance, 9-oxodec-trans-2-enoic acid, a honeybee pheromone. Proc. Royal Soc. B 155(960): 417-432.

Cain K., S.B. Bratton, G.M. Cohen. (2002) The Apaf-1 apoptosome: a large caspase-activating complex. Biochimie 84(2-3): 203-214.

Cardoso - Júnior C.A.M., B.P. Oldroyd, I. Ronai. (2021) Vitellogenin expression in the ovaries of adult honeybee workers provides insights into the evolution of reproductive and social traits. Insect Mol. Biol.

Cavaliere V., C. Taddei, G. Gargiulo. (1998) Apoptosis of nurse cells at the late stages of oogenesis of Drosophila melanogaster. Dev Gen Evol 208(2): 106-112.

Cruz-Landim C., K. Patrício, W.F. Antonialli Jr. (2006) Cell death and ovarian development in highly eusocial bees (Hymenoptera, Apidae): caste differentiation and worker egg laying. Braz. J. Morphol. Sci 23: 27-42.

Dade H.A. (1977) Anatomy and dissection of the honeybee. International Bee Research Association, London. 
735

736

737

738

739

740

741

742

743

744

745

746

747

748

749

750

751

752

753

754

755

756

757

758

759

760

761

762

763

764

765

766

767

768

769

770

Dallacqua R.P., M.M.G. Bitondi. (2014) Dimorphic ovary differentiation in honeybee (Apis mellifera) larvae involves caste-specific expression of homologs of Ark and Buffy cell death genes. PloS one 9(5): e98088.

Dolezal A.G., K.B. Flores, K.S. Traynor, G.V. Amdam. (2013) The evolution and development of eusocial insect behavior, in: Streelman J.T. (Ed.), Advances in Evolutionary Developmental Biology, Wiley-Blackwell, Hoboken, New Jersey, pp. 37-57.

Drummond-Barbosa D., A.C. Spradling. (2001) Stem cells and their progeny respond to nutritional changes during Drosophila oogenesis. Dev. Biol. 231(1): 265-278.

Duncan E.J., O. Hyink, P.K. Dearden. (2016) Notch signalling mediates reproductive constraint in the adult worker honeybee. Nat. Commun 7: 12427.

Engels W. (1974) Occurrence and significance of vitellogenins in female castes of social Hymenoptera. Am. Zool. 14(4): 1229-1237.

Etchegaray J.I., A.K. Timmons, A.P. Klein, T.L. Pritchett, E. Welch, et al. (2012) Draper acts through the JNK pathway to control synchronous engulfment of dying germline cells by follicular epithelial cells. Development 139(21): 4029-4039.

Fine J.D., H.Y. Shpigler, A.M. Ray, N.J. Beach, A.L. Sankey, et al. (2018) Quantifying the effects of pollen nutrition on honey bee queen egg laying with a new laboratory system. PloS one 13(9).

Giorgi F., P. Deri. (1976) Cell death in ovarian chambers of Drosophila melanogaster. Development 35(3): 521-533.

Grozinger C.M., J. Richards, H.R. Mattila. (2014) From molecules to societies: mechanisms regulating swarming behavior in honey bees (Apis spp.). Apidologie 45(3): 327-346.

Gruntenko N., M. Bownes, J. Terashima, M.Z. Sukhanova, I.Y. Raushenbach. (2003) Heat stress affects oogenesis differently in wild - type Drosophila virilis and a mutant with altered juvenile hormone and 20 - hydroxyecdysone levels. Insect Mol. Biol. 12(4): 393-404.

Guidugli-Lazzarini K.R., A.M. do Nascimento, E.D. Tanaka, M.D. Piulachs, K. Hartfelder, et al. (2008) Expression analysis of putative vitellogenin and lipophorin receptors in honey bee (Apis mellifera L.) queens and workers. J. Insect Physiol. 54(7): 1138-1147.

Guidugli K.R., A.M. Nascimento, G.V. Amdam, A.R. Barchuk, S. Omholt, et al. (2005) Vitellogenin regulates hormonal dynamics in the worker caste of a eusocial insect. FEBS letters 579(22): 4961-4965.

Gutzeit H., D. Zissler, R. Fleig. (1993) Oogenesis in the honeybee Apis mellifera: cytological observations on the formation and differentiation of previtellogenic ovarian follicles. Roux's Arch. Dev. Biol. 202(3): 181-191.

Hansen I.A., G.M. Attardo, S.G. Roy, A.S. Raikhel. (2005) Target of rapamycin-dependent activation of $\mathrm{S} 6$ kinase is a central step in the transduction of nutritional signals during egg development in a mosquito. J. Biol. Chem. 280(21): 20565-20572.

Hartfelder K., G.J. Tiberio, D.C. Lago, R.P. Dallacqua, M.M.G. Bitondi. (2018) The ovary and its genes-developmental processes underlying the establishment and function of a highly divergent reproductive system in the female castes of the honey bee, Apis mellifera. Apidologie 49(1): 49-70.

Hodin J. (2009) She shapes events as they come: plasticity in female insect reproduction, in: Whitmen W.D. (Ed.), Phenotypic plasticity of insects: mechanisms and consequences, Science Publishers, Enfield, NH, USA, pp. 423-521.

Hoover S.E., C.I. Keeling, M.L. Winston, K.N. Slessor. (2003) The effect of queen pheromones on worker honey bee ovary development. Naturwissenschaften 90(10): 477-480. 
Hopkins C., P. King. (1964) Egg resorption in Nasonia vitripennis (Walker)(Hymenoptera: Pteromalidae), Proceedings of the Royal Entomological Society of London. Series A, General Entomology, Wiley Online Library, pp. 101-107.

Hunt J.H., G.V. Amdam. (2005) Bivoltinism as an antecedent to eusociality in the paper wasp genus Polistes. Science 308(5719): 264-267.

Jenkins V.K., A.K. Timmons, K. McCall. (2013) Diversity of cell death pathways: insight from the fly ovary. Trends Cell Biol. 23(11): 567-574.

Jouandin P., C. Ghiglione, S. Noselli. (2014) Starvation induces FoxO-dependent mitotic-toendocycle switch pausing during Drosophila oogenesis. Development 141(15): 30133021.

King R.C. (1970) Ovarian development in Drosophila melanogaster. Academic Press, New York.

Lago D.C., F.C. Humann, A.R. Barchuk, K.J. Abraham, K. Hartfelder. (2016) Differential gene expression underlying ovarian phenotype determination in honey bee, Apis mellifera L., caste development. Insect Biochem. Mol. Biol. 79: 1-12.

Laidlaw H.H., R.E. Page. (1997) Queen rearing and bee breeding. Wicwas Press, Cheshire, CT. Le Conte Y., A. Mohammedi, G.E. Robinson. (2001) Primer effects of a brood pheromone on honeybee behavioural development. Proc. Royal Soc. B 268(1463): 163-168.

Lourenço A.P., A. Mackert, A. dos Santos Cristino, Z.L.P. Simões. (2008) Validation of reference genes for gene expression studies in the honey bee, Apis mellifera, by quantitative real-time RT-PCR. Apidologie 39(3): 372-385.

Malka O., S. Shnieor, A. Hefetz, T. Katzav-Gozansky. (2007) Reversible royalty in worker honeybees (Apis mellifera) under the queen influence. Behav Ecol Sociobiol 61(3): 465-473.

Mattila H.R., G.W. Otis. (2007) Dwindling pollen resources trigger the transition to broodless populations of long - lived honeybees each autumn. Ecological Entomology 32(5): 496-505.

Minakuchi C., T. Namiki, T. Shinoda. (2009) Krüppel homolog 1, an early juvenile hormoneresponse gene downstream of Methoprene-tolerant, mediates its anti-metamorphic action in the red flour beetle Tribolium castaneum. Dev. Biol. 325(2): 341-350.

Mpakou V.E., A.D. Velentzas, P.D. Velentzas, L.H. Margaritis, D.J. Stravopodis, et al. (2011) Programmed cell death of the ovarian nurse cells during oogenesis of the ladybird beetle Adalia bipunctata (Coleoptera: Coccinellidae). Dev. Growth Differ. 53(6): 804815.

Oster G.F., E.O. Wilson. (1978) Caste and ecology in the social insects. Princeton University Press, Princeton

Page R., E. Erickson. (1988) Reproduction by worker honey bees (Apis mellifera L.). Behav Ecol Sociobiol 23(2): 117-126.

Page R.E., G.E. Robinson. (1994) Reproductive competition in queenless honey bee colonies (Apis mellifera L.). Behav Ecol Sociobiol 35(2): 99-107.

Perez-Hedo M., C. Rivera-Perez, F.G. Noriega. (2014) Starvation increases insulin sensitivity and reduces juvenile hormone synthesis in mosquitoes. PLoS One 9(1): e86183.

Pfaffl M.W., A. Tichopad, C. Prgomet, T.P. Neuvians. (2004) Determination of stable housekeeping genes, differentially regulated target genes and sample integrity: BestKeeper-Excel-based tool using pair-wise correlations. Biotechnology letters 26(6): 509-515. 
817

818

819

820

821

822

823

824

825

826

827

828

829

830

831

832

833

834

835

836

837

838

839

840

841

842

843

844

845

846

847

848

849

850

851

852

853

854

855

856

857

858

859

860

861
Pierce A.L., L.A. Lewis, S.S. Schneider. (2007) The use of the vibration signal and worker piping to influence queen behavior during swarming in honey bees, Apis mellifera. Ethology 113(3): 267-275.

Pritchett T., K. McCall. (2012) Role of the insulin/Tor signaling network in starvation-induced programmed cell death in Drosophila oogenesis. Cell Death Differ. 19(6): 1069.

Raikhel A.S., T. Dhadialla. (1992) Accumulation of yolk proteins in insect oocytes. Annu Rev Entomol 37(1): 217-251.

Ratnieks F.L. (1993) Egg-laying, egg-removal, and ovary development by workers in queenright honey bee colonies. Behav Ecol Sociobiol 32(3): 191-198.

Reim T., M. Thamm, D. Rolke, W. Blenau, R. Scheiner. (2013) Suitability of three common reference genes for quantitative real-time PCR in honey bees. Apidologie 44(3): 342350.

Rhodes J.W., D.C. Somerville, S. Harden. (2004) Queen honey bee introduction and early survival-effects of queen age at introduction. Apidologie 35(4): 383-388.

Robinson G.E., C. Strambi, A. Strambi, Z.-Y. Huang. (1992) Reproduction in worker honey bees is associated with low juvenile hormone titers and rates of biosynthesis. Gen. Comp. Endocrinol. 87(3): 471-480.

Rodriguez A., H. Oliver, H. Zou, P. Chen, X. Wang, et al. (1999) Dark is a Drosophila homologue of Apaf-1/CED-4 and functions in an evolutionarily conserved death pathway. Nature cell biology 1(5): 272.

Ronai I., M.H. Allsopp, K. Tan, S. Dong, X. Liu, et al. (2017) The dynamic association between ovariole loss and sterility in adult honeybee workers. Proc. R. Soc. B 284(1851): 20162693.

Ronai I., D.A. Barton, B.P. Oldroyd, V. Vergoz. (2015) Regulation of oogenesis in honey bee workers via programed cell death. J. Insect Physiol. 81: 36-41.

Ronai I., B. Oldroyd, V. Vergoz. (2016) Queen pheromone regulates programmed cell death in the honey bee worker ovary. Insect Mol. Biol. 25(5): 646-652.

Ronai I., B.P. Oldroyd, D.A. Barton, G. Cabanes, J. Lim, et al. (2016) Anarchy is a molecular signature of worker sterility in the honey bee. Mol. Biol. Evol. 33(1): 134-142.

Ronai I., V. Vergoz, B. Oldroyd. (2016) The mechanistic, genetic, and evolutionary basis of worker sterility in the social hymenoptera. Advances in the Study of Behavior 48: 251-317.

Rozen J. (1986) Survey of the number of ovarioles in various taxa of bees (Hymenoptera: Apoidea). Proceedings of the Entomological Society of Washington (USA) 88: 707710.

Seeley T. (1985) Honey bee ecology Princeton University Press, Princeton.

Seeley T.D., R.D. Fell. (1981) Queen substance production in honey bee (Apis mellifera) colonies preparing to swarm (Hymenoptera: Apidae). J. Kans. Entomol. Soc.: 192-196.

Shehata S., G. Townsend, R. Shuel. (1981) Seasonal physiological changes in queen and worker honeybees. J Apic Res 20(2): 69-78.

Simpson J. (1959) Variation in the incidence of swarming among colonies of Apis mellifera throughout the summer. Ins Soc 6(1): 85-99.

Smykal V., A.S. Raikhel. (2015) Nutritional control of insect reproduction. Curr. Opin. Insect. Sci. 11: 31-38.

Snodgrass R.E. (1956) Anatomy of the honey bee. Cornell University Press. 
862

863

864

865

866

867

868

869

870

871

872

873

874

875

876

877

878

879

880

881

882

883

884

885

886

887

888

889

890

891

892

893

894

895

896

897

898

899

900

901

902

903

904

905

906
Spradling A. (1993) Developmental genetics of oogenesis, in: Bate M. and Arias A.M. (Eds.), The development of Drosophila melanogaster, Cold Spring Harbor Lab. Press, New York, pp. 1-70.

Szabo T. (1974) Behavioural studies on queen introduction in the honeybee II. effect of the age of workers (from a colony with a laying queen) on their behaviour towards an introduced virgin queen. J Apic Res 13(2): 127-135.

Tanaka E., I. Schmidt-Capella, K. Hartfelder. (2006) Cell death in the germline-mechanisms and consequences for reproductive plasticity in social bees. Braz. j. morphol. sci. 23(1).

Tanaka E.D., K. Hartfelder. (2004) The initial stages of oogenesis and their relation to differential fertility in the honey bee (Apis mellifera) castes. Arthropod Struct Dev 33(4): 431-442.

Tanner E.A., T.A. Blute, C.B. Brachmann, K. McCall. (2011) Bcl-2 proteins and autophagy regulate mitochondrial dynamics during programmed cell death in the Drosophila ovary. Development 138(2): 327-338.

Terashima J., M. Bownes. (2004) Translating available food into the number of eggs laid by Drosophila melanogaster. Genetics 167(4): 1711-1719.

Toth A.L., K. Varala, T.C. Newman, F.E. Miguez, S.K. Hutchison, et al. (2007) Wasp gene expression supports an evolutionary link between maternal behavior and eusociality. Science 318(5849): 441-444.

Traynor K.S., Y. Le Conte, R.E. Page. (2014) Queen and young larval pheromones impact nursing and reproductive physiology of honey bee (Apis mellifera) workers. Behav Ecol Sociobiol 68(12): 2059-2073.

Tufail M., M. Takeda. (2008) Molecular characteristics of insect vitellogenins. J. Insect Physiol. 54(12): 1447-1458.

Uchida K., M. Nishizuka, D. Ohmori, T. Ueno, Y. Eshita, et al. (2004) Follicular epithelial cell apoptosis of atretic follicles within developing ovaries of the mosquito Culex pipiens pallens. J. Insect Physiol. 50(10): 903-912.

Velentzas A.D., I.P. Nezis, D.J. Stravopodis, I.S. Papassideri, L.H. Margaritis. (2003) Stagespecific regulation of programmed cell death during oogenesis of the medfly Ceratitis capitata (Diptera, Tephritidae). Int. J. Dev. Biol. 51(1): 57-66.

Visscher P.K. (1989) A quantitative study of worker reproduction in honey bee colonies. Behav Ecol Sociobiol 25(4): 247-254.

West-Eberhard M.J. (1987) Flexible strategy and social evolution. Animal societies. Theories and facts.

Wheeler D., N. Buck, J. Evans. (2014) Expression of insulin/insulin - like signalling and TOR pathway genes in honey bee caste determination. Insect Mol. Biol. 23(1): 113-121.

Winston M.L. (1987) The biology of the honey bee. Harvard university press, Cambridge MA. Woyciechowski M., K. Kuszewska. (2012) Swarming generates rebel workers in honeybees. Curr. Biol. 22(8): 707-711. 


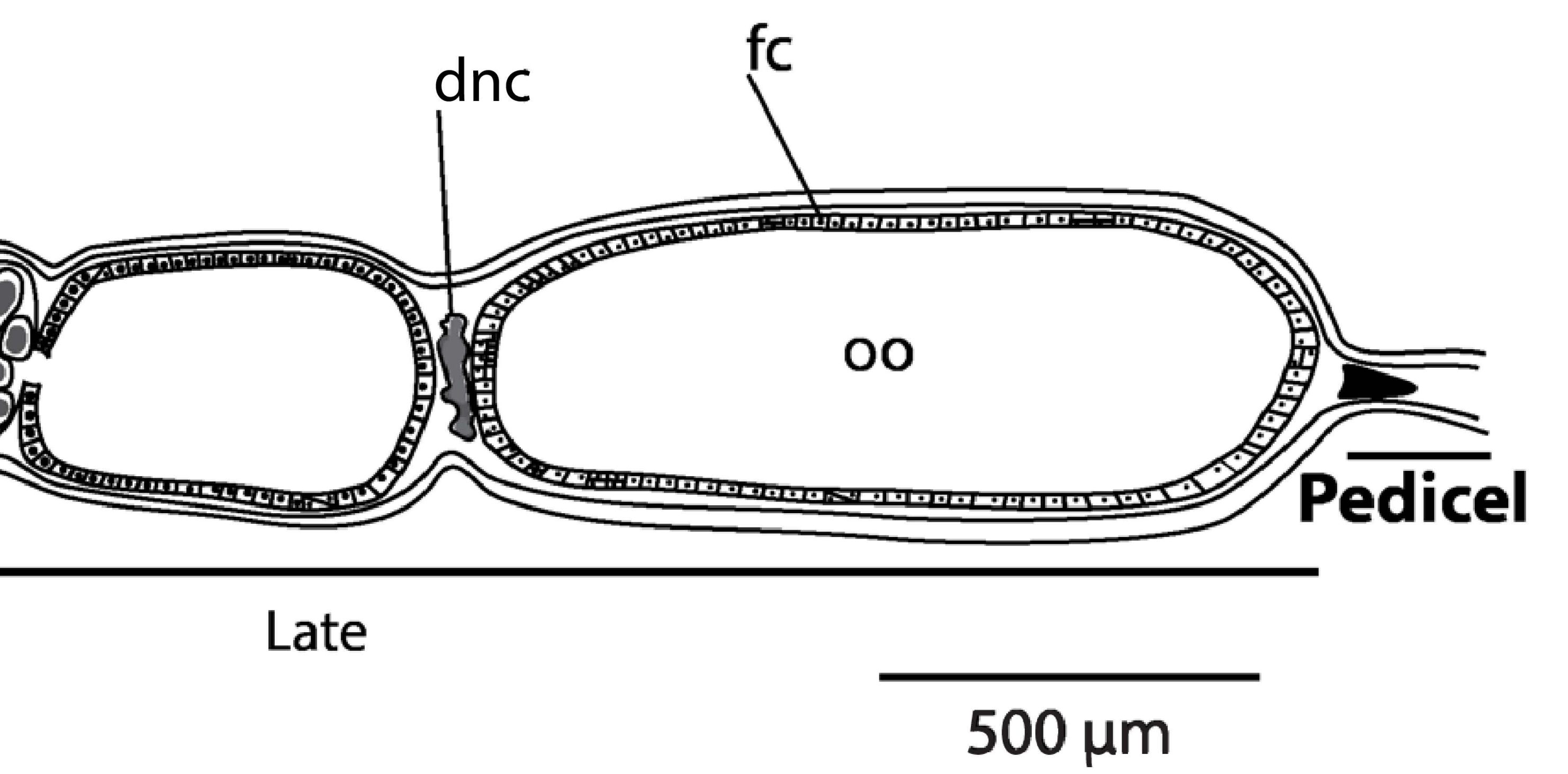

Apical tip
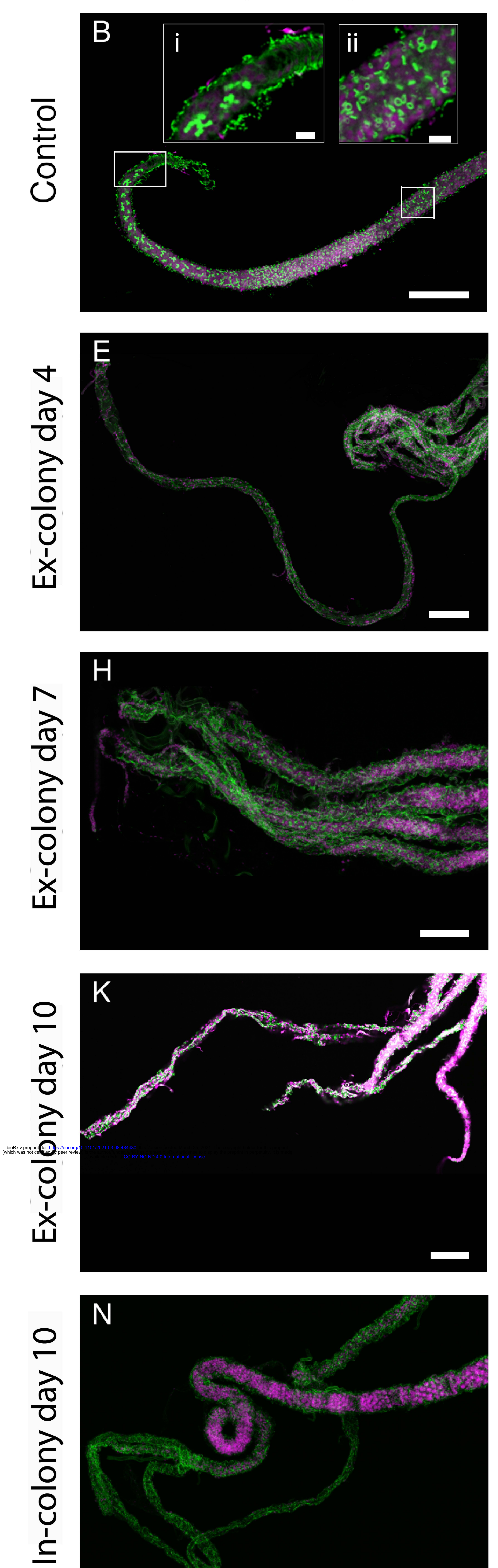

Early

itellarium

Middle
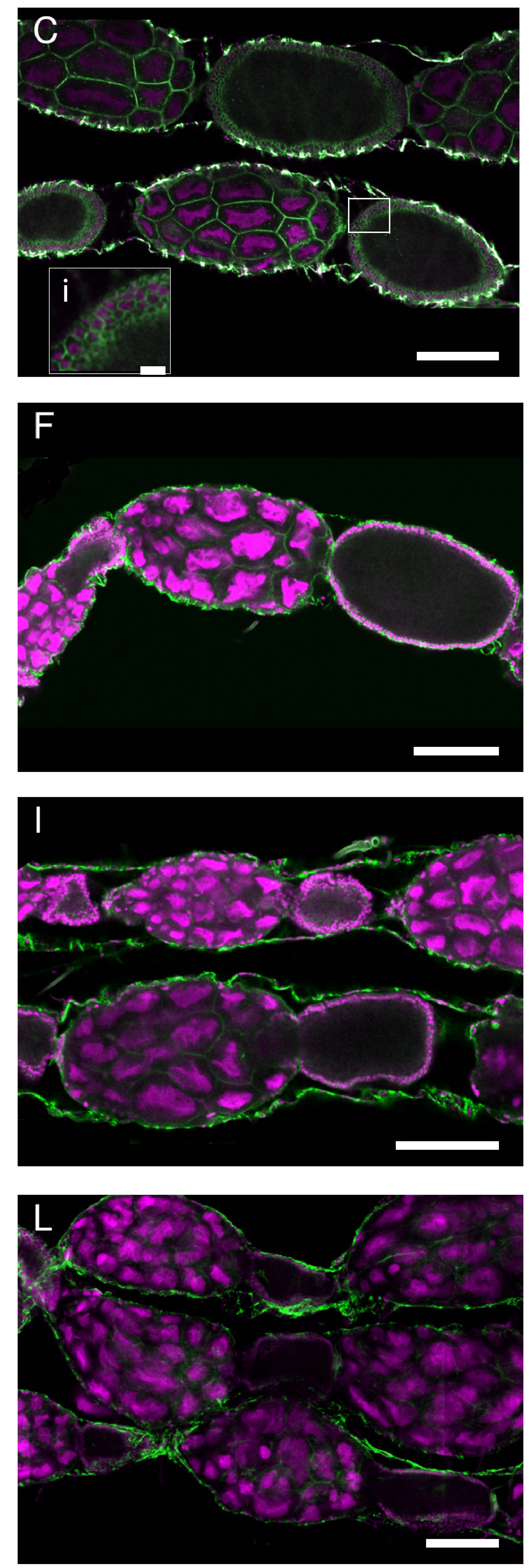

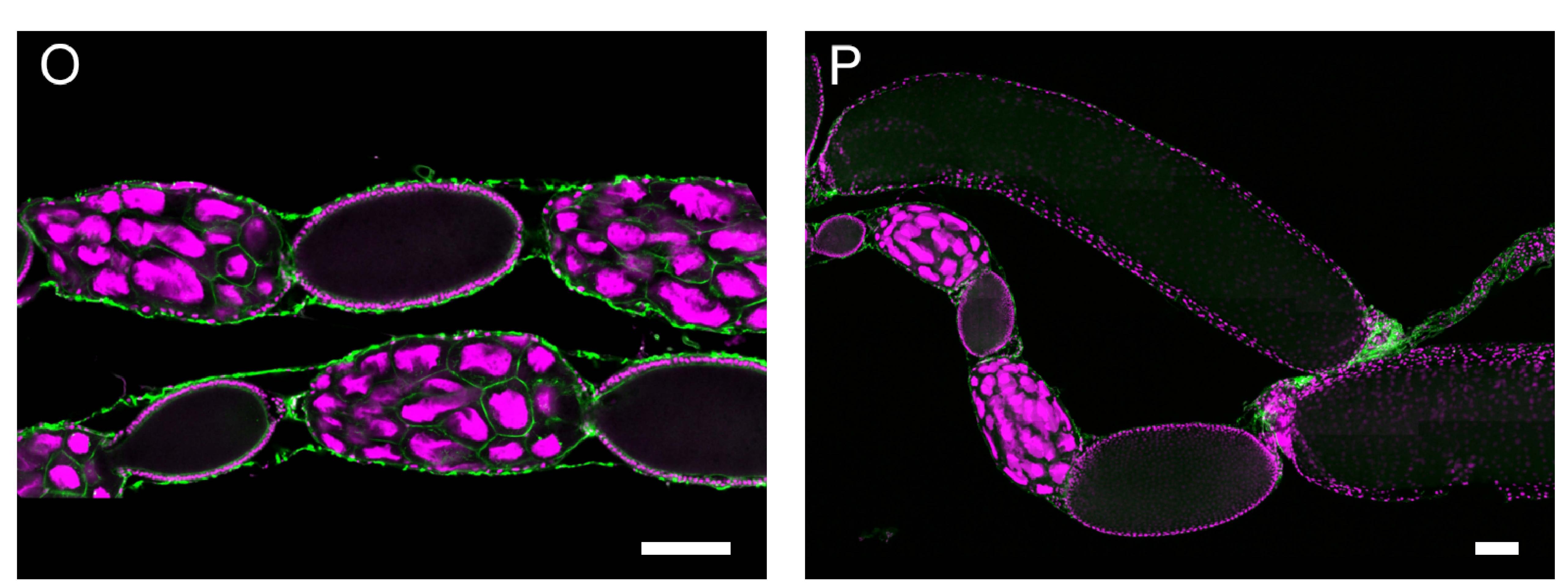


Ex-colony Day $4 \quad$ Ex-colony Day 7 


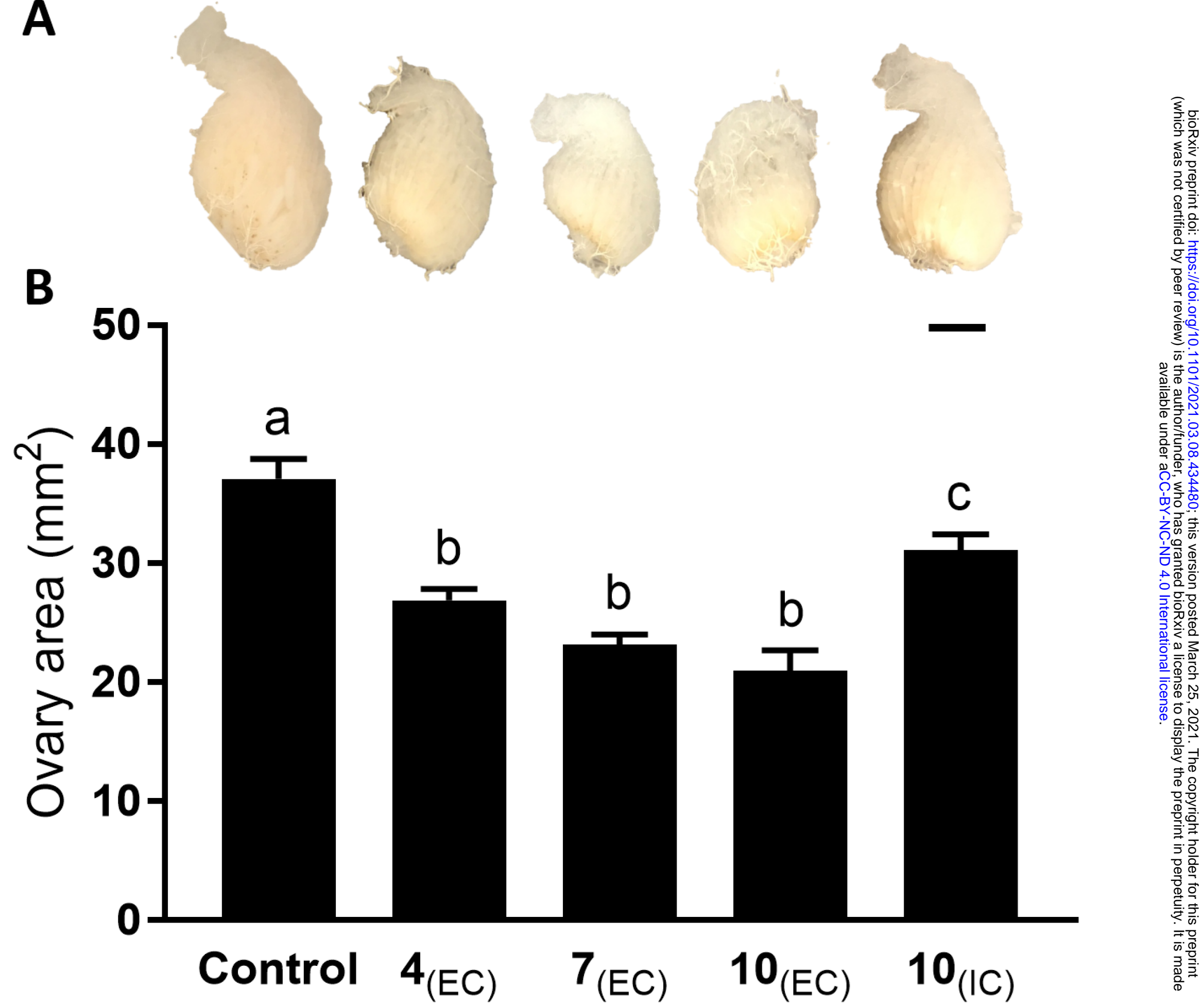

Days caged 

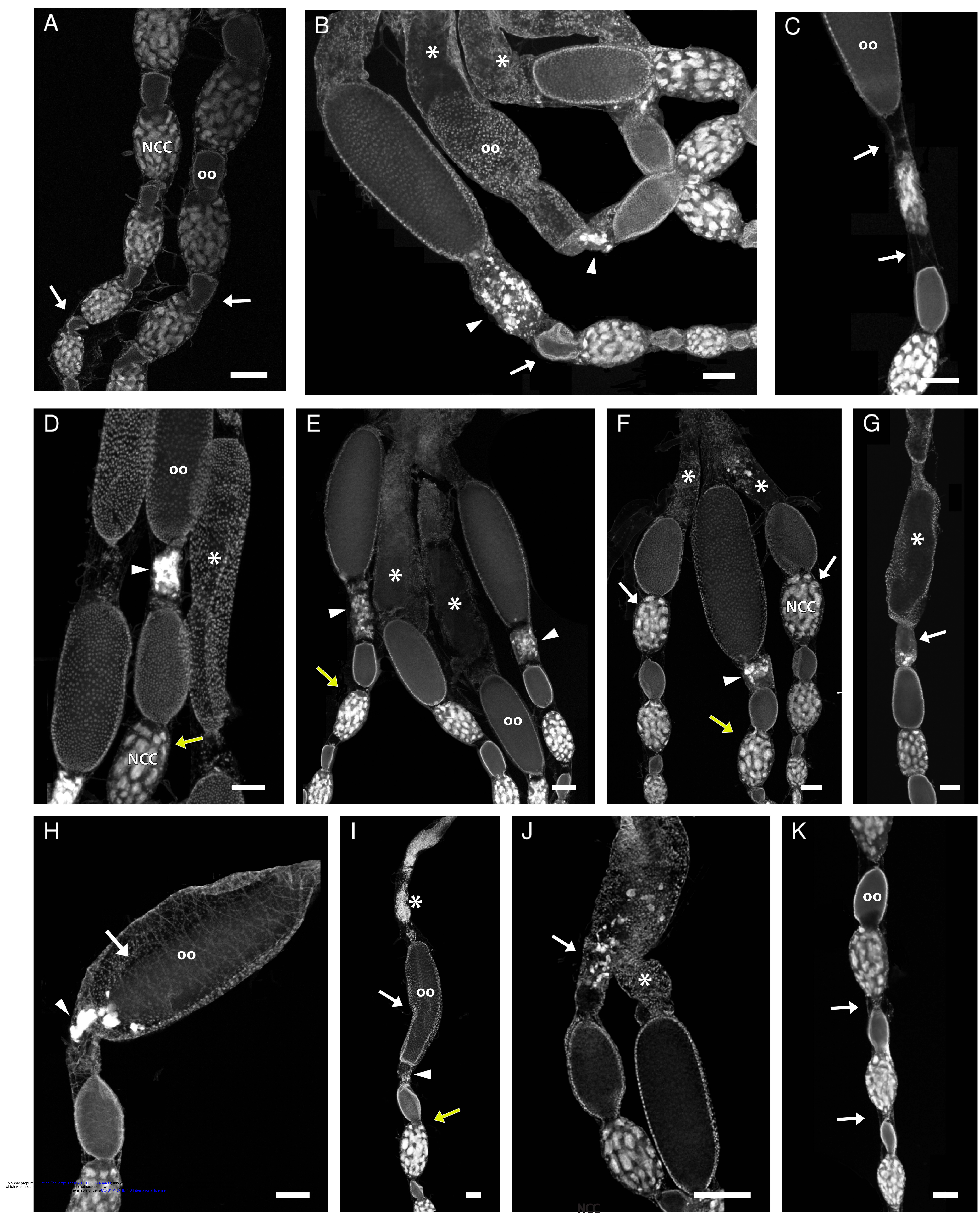


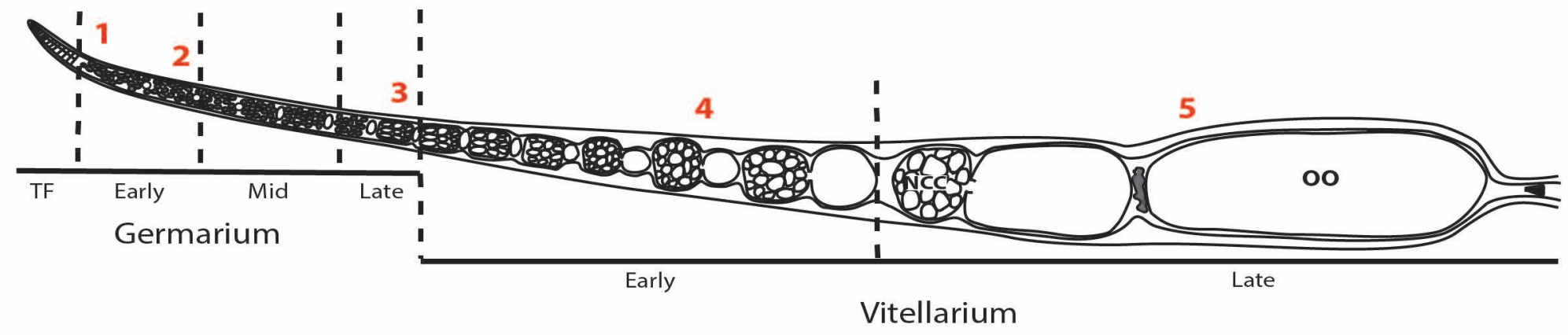

B

$\begin{array}{lllll}1 & 2 & 3 & 4 & 5\end{array}$ Stem cells Early germarium Late germarium Early vitellarium Late vitellarium

Honey bee mated queen
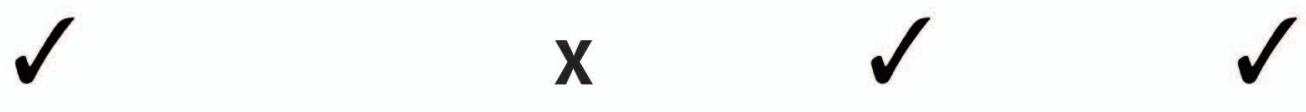

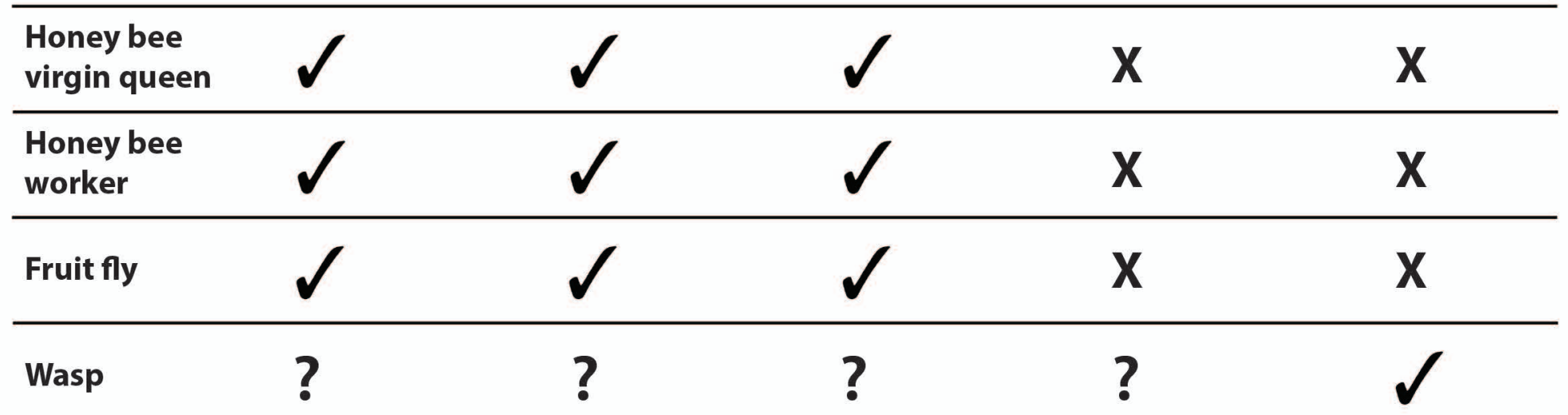

